BLS 32, No 1 2006. DOI: http://dx.doi.org/10.3765/bls.v32i1.3480 (published by the Berkeley Linguistics Society and the Linguistic Society of America)

\title{
The Effects of Lexical Frequency and Stress on Coarticulation
}

\author{
GWANHI YUN \\ University of Arizona, Tucson
}

\section{Introduction}

It has increasingly been observed that lexical frequency plays a significant role in English phonology (vowel reduction: Fidelholtz 1975, Hooper 1976; lexical diffusion: Bybee 2002; cyclic stress: Hammond 2004). For example, highfrequency words undergo more word-initial vowel reduction in closed syllables as in (1a) (Fidelholtz 1975). In addition, medial vowel elision occurs to a greater extent in relatively high-frequency words than in low-frequency words as in (1b) (Hooper 1976, Bybee 2002). Furthermore, fixed phrases show more regular rhythmic alternation than less fixed phrases as in (1c) (Liberman and Prince 1977, Hayes 1984, Hammond 1988). High-frequency words also exhibit more medial clash-based de-stressing and vowel reduction for secondary stressed vowels than low-frequency words as in (1d) (Hammond 2005). Lastly, phrases with high transitional probability are more likely to undergo palatalization than those with low transitional probability as in (1e) (Bush 2001).

$\begin{array}{cllll}\text { (1) a. } & \text { astrónomy } & \text { vs. } & \text { gàstrónomy } & \\ & \text { mistáke } & \text { vs. } & \text { mistóok } & \\ \text { b. } & \text { mém(o)ry } & \text { vs. } & { }^{*} \text { mamm(o)ry } & \text { vs. mámmory } \\ & \text { núrs(e)ry } & \text { vs. } & { }^{*} \text { curs(o)ry } & \text { vs. cúrsory } \\ \text { c. } & \text { bámbòo cúrtain } & \text { vs. } & \text { bàmbóo fénce } & \\ \text { d. } & \text { trànsformátion } & \text { vs. } & \text { èxàltátion } & \\ & \text { ìnformátion } & \text { vs. } & \text { àttèstátion } & \\ & \text { trànsportátion } & \text { vs. } & \text { òstèntátion } & \\ \text { e. } & \text { did you } & \text { vs. } & \text { had you } & \end{array}$

However, there have been very few studies on how word frequency or degree of stress affects inter-gestural timing relations such as in vowel-to-vowel (V-to-V) coarticulation. In this paper, we report new findings from acoustic experiments investigating how word frequency is related to the degree of $\mathrm{V}$-to- $\mathrm{V}$ coarticulation and how degrees of stress affect the degree of V-to- $\mathrm{V}$ coarticulation in English. 
Gwanhi Yun

According to articulatory phonology, coarticulation has been defined as "patterns of coordination, between the articulatory gestures of neighboring segments, which result in the vocal tract responding at any one time to commands for more than one segment" (Manuel 1987:179). Put simply, coarticulation is coproduction, referring to the temporal co-occurrence or overlap in the articulation of two (or more) gestures (Browman and Goldstein 1989, Byrd 1996:210). With respect to the effect of stress on V-to-V coarticulation, Magen (1984) showed that carryover coarticulation occurs from stressed vowels to unstressed vowels within the foot in English and Japanese. In addition, Magen's (1997) acoustic study revealed that bidirectional coarticulation takes place in English centering on unstressed vowels, as illustrated in (2).

(2) Bidirectional coarticulation

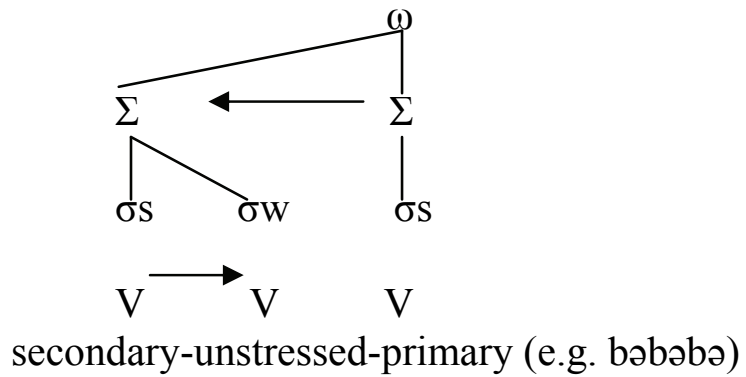

As seen above, primary stressed vowels influence secondary stressed vowels across unstressed vowels, and secondary stressed vowels affect unstressed vowels within the same foot. Magen's study has two important implications with respect to the directionality and domain of V-to-V coarticulation. First, vowels with a higher degree of stress affect vowels with a lower degree of stress. Second, coarticulation occurs even across foot boundaries. However, my research is different from Magen's $(1984,1997)$ studies in that it attempts to see how vowels with different degrees of stress can be resistant to coarticulation from unstressed vowels. Furthermore, I employed real English words rather than hypothetical words like Magen (1997). Thus, this research will reveal new ways to see the directionality of coarticulation as well as the degree of resistance to coarticulation with respect to the effect of stress.

\section{Goals}

This study has three goals. First, we attempt to see whether/how much lexical frequency affects fine phonetic details at the subphonemic level such as the degree of coarticulation. The second goal is to look into whether/how much stress affects resistance to coarticulation. The last objective is to explore the possibility that different intergestural timing relations can be represented in the lexicon. 


\section{Lexical Frequency and Degree of V-to-V Coarticulation 2.1. Ultrasound Experiments}

To seek an answer for whether word frequency directly influences the degree of coarticulation, a preliminary articulatory experiment was conducted. Since highfrequency words show more efficiency in production than low-frequency words (Bybee 2002), it is reasonable to speculate that intergestural timing organization is more variable and is more likely to be overlapped between vowels in highfrequency words than in low-frequency words. Thus, the following hypothesis is proposed:

(3) "Frequency-strengthened intergestural timing relations" hypothesis The degree of V-to-V coarticulation may be stronger in high-frequency words than in low-frequency words.

To test this hypothesis, one native speaker of English participated in the production of English words. The subject was an adult male in his 30s. Two- and three-syllable words containing $\mathrm{V}_{1} \mathrm{CV}_{2}$ sequences and identical foot structure were used as stimuli. $V_{1}$ varied among back/front low $/ \mathrm{mid}$ vowels such as $/ \mathrm{a}$, $\mathfrak{x}$, $\supset, \Lambda /$, and the intervening consonants varied among labials, alveolars, and velars. $\mathrm{V}_{2}$ was either $/ \mathrm{i} /$ or $/ \mathrm{I} /$. The materials were randomly selected from the Brown corpus (with 1,026,604 words). Low-frequency words have counts ranging from $1-50$, while high-frequency words have counts above 50 , as illustrated in (4). The numbers in parentheses after each word refer to the token frequency of each word.

\begin{tabular}{|c|c|c|}
\hline$\underline{\mathrm{V}}_{1} \underline{\mathrm{V}}_{2}$ & Low-frequency $(1-50)$ & High-frequency $(50-400)$ \\
\hline$a-\bar{i}$ & barley (6) / bobby (25) & party/army (132) \\
\hline a-I & cottage (19) & college (271) \\
\hline æ-i & alley $(8)$ & cärry (88) \\
\hline æ-I & savagage (22) & average (132) \\
\hline$\Lambda-\mathrm{i}$ & cunning (5) & cutting (69) \\
\hline $0-i$ & longing (10) / sausage (2) & morning (214) \\
\hline
\end{tabular}

Both high- and low-frequency words were displayed on a monitor in front of the subject in the carrier phrase "Please say to me." Each word was uttered three times. A total of 21 tokens were produced for each word, and in all, 63 of their recorded images were analyzed. The height (or frontness) of the tongue body was measured on the basis of ultrasound images recorded as digital video. In order to quantify the tongue shape, Palatoglossatron was used (Baker 2006), and to get statistical results, smoothing spline ANOVA was used (Davidson 2005).

Since it is difficult to see the relative backness of the tongue body from one picture, average tongue body lines were obtained for statistical analysis as illustrated in (5) (Davidson 2005). The thick lines refer to the tongue body position of back vowels in low-frequency words, and the thin lines to the tongue body of 
Gwanhi Yun

back vowels in high-frequency words. The left side of each graph shows the tongue back or root, while the right side shows the tongue front or tip.

(5)

a. barley vs. party

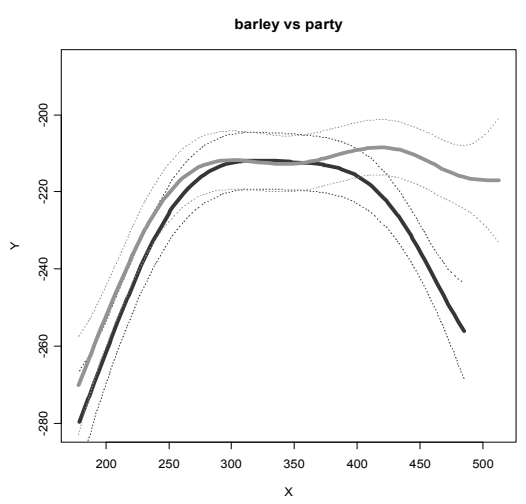

b. longing vs. morning

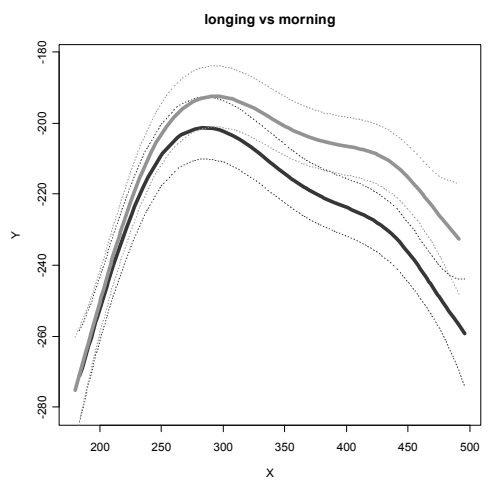

As expected, the low or mid vowels in high-frequency words such as party, cutting, and morning were, interestingly, articulated significantly higher and fronter than those in low-frequency words such as barley, cunning, and longing along some part of the tongue body. Only a pair such as bobby-army showed an exceptional pattern. That is, stronger anticipatory coarticulation of $V_{1}$ from $V_{2}$ occurred in high-frequency words than in low-frequency words. These results support the hypothesis that intergestural timing relations between vowels are more overlapped in high-frequency words than in low-frequency words.

In order to confirm these articulatory results, acoustic experiments were conducted by measuring F1 and F2 values, which will be shown in next section.

\subsection{Acoustic Experiments: F1/F2 Coarticulation}

To test the "frequency-strengthened intergestural timing relations" hypothesis in (3), four native speakers of English participated in the production of English words. They were all in their 20s; three were females, and one was male. The same stimuli used in the ultrasound experiments were uttered five times. F1/F2 values of low or mid vowels were compared between high-frequency words and low-frequency words in order to see how high/front the vowels are articulated. In total, 105 tokens were analyzed, and F1/F2 values were measured at three time points in $\mathrm{V}_{1}$ of the $\mathrm{V}_{1} \mathrm{CV}_{2}$ sequences (i.e. onset, middle, offset) in Praat (Boersma and Weenink 2001). We expected that $F 1$ values of $V_{1}$ (e.g. back vowels) would be lower in high-frequency words than in low-frequency words as a result of stronger anticipatory coarticulation from $\mathrm{V}_{2}$ (e.g. /i/) with respect to vowel height. Furthermore, it was expected that F2 values would be higher in high-frequency words than in low-frequency words as a result of stronger coarticulation effects in terms of the backness of $\mathrm{V}_{1} \mathrm{~s}$.

A one-factor ANOVA revealed that the frequency effect on the degree of $\mathrm{V}$ to- $\mathrm{V}$ coarticulation was significant as illustrated in $(6)(p<0.05)$. As predicted, F1s of $\mathrm{V}_{1}$ such as back vowels /a,,$\Lambda /$ were significantly lower in high-frequency 


\section{Lexical Frequency, Stress, and Coarticulation}

words than in low-frequency words. Furthermore, F2s of the same back vowels were higher in high-frequency words than in low-frequency words. These results indicate that $\mathrm{V}_{1}$ underwent stronger anticipatory coarticulation from $\mathrm{V}_{2}$ in highfrequency words than in low-frequency words.

(6) Frequency effects: within-subjects ANOVA

\begin{tabular}{|l|c|c|c|c|}
\cline { 2 - 5 } \multicolumn{1}{c|}{} & \multicolumn{4}{c|}{ F1 (Hz) } \\
\cline { 2 - 5 } \multicolumn{1}{c|}{} & Mean & Std. Dev. & Difference & $p$-value \\
\hline Lo-Freq. & 877 & 174.45 & & $p<0.05$ \\
\hline Hi-Freq. & 765 & 226.82 & -111.7 & \\
\hline & \multicolumn{4}{|c|}{ F2 (Hz) } \\
\hline Lo-Freq. & 1559 & 371.38 & 135.9 & $p \leq 0.05$ \\
\hline Hi-Freq. & 1695 & 469.86 & & \\
\hline
\end{tabular}

Overall, the results support the proposed hypothesis, showing that a $\mathrm{V}_{1}$ such as a back vowel is articulated further front and higher in high-frequency words than in low-frequency words due to the influence of a $V_{2}$ such as /i/. However, since (6) shows F1/F2 coarticulation only at the midpoint of $V_{1}, F 1$ values were measured at the initial and offset points in order to check for consistent patterns during the whole production of $\mathrm{V}_{1}$ in $\mathrm{V}_{1} \mathrm{CV}_{2}$ sequences. The whole ranges of $\mathrm{F} 1$ in a $\mathrm{V}_{1}$ such as a back vowel were lower in high-frequency words than in lowfrequency words as illustrated in (7). The thin lines with a lower F1 range refer to the stream of $\mathrm{F} 1$ in $\mathrm{V}_{1}$ of high-frequency words, while the thick lines with a higher $\mathrm{F} 1$ range refer to the stream of $\mathrm{F} 1$ in $\mathrm{V}_{1}$ of low-frequency words. In particular, (7a), (7b), and (7c) show that stronger anticipatory coarticulation began from the onset or midpoint of $\mathrm{V}_{1}$. An interesting implication here is that speakers plan to produce $V_{2}$ even while they are producing $V_{1}$ in a $V_{1} C V_{2}$ sequence (Whalen 1990). Furthermore, as seen in the pair alley vs. carry (7c), when $\mathrm{V}_{1}$ was a front vowel, $\mathrm{F} 1$ of $\mathrm{V}_{1}$ showed a greater difference than in the other pairs.

a. barley vs. party

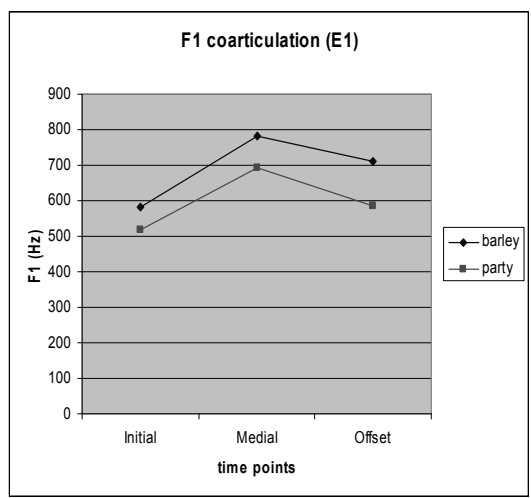

b. bobby vs. army

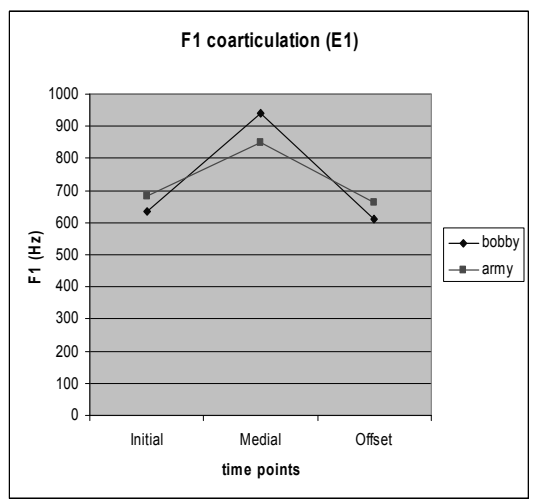


Gwanhi Yun

c. alley vs. carry

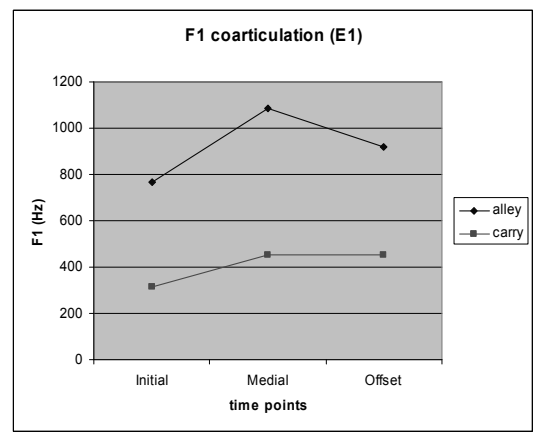

d. cutting vs. cunnning

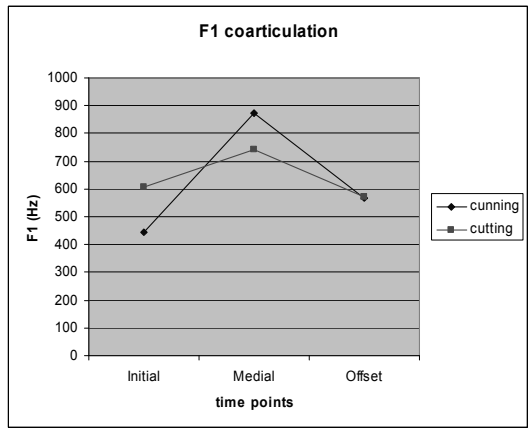

The results above also confirm Öhman's (1966) 'dual mode' idea that VCV sequences are realized by means of an underlying V-to-V articulatory mode, with a superimposed consonantal gesture. In brief, they support the hypothesis that high word frequency causes greater gestural overlap than low word frequency.

\section{Stress Effects on Resistance to Coarticulation}

\subsection{Ultrasound Experiments}

Preliminary articulatory experiments were conducted with ultrasound to answer the following question: does the degree of stress affect the degree of or resistance to coarticulation? Magen's $(1985,1997)$ studies focus on the directionality of Vto- $\mathrm{V}$ coarticulation with respect to stress differences, whereas I attempt to reveal the effect of stress differences on the degree of $\mathrm{V}$-to-V coarticulation. Another difference lies in that my investigation focuses on whether even unstressed vowels affect primary and/or secondary stressed vowels in English.

It is known that since primary stressed vowels show longer duration and higher amplitude than secondary stressed vowels, they are more resistant to coarticulation, and therefore intergestural timing organization between a primary stressed vowel and the following vowel is less overlapped than between a secondary stressed vowel and the following vowel (Edward et al. 1991). This basic reasoning leads us to propose the following hypothesis:

"Stress-dependent intergestural timing relations" hypothesis

The degree of V-to-V coarticulation may be stronger in secondary stressed vowels than in primary stressed vowels.

This hypothesis predicted that a $V_{1}$ with secondary stress would be articulated higher than one with primary stress because of stronger anticipatory coarticulation from an unstressed $V_{2}$, and that $F 1$ values of $V_{1}$ with secondary stress would be lower than those of $\mathrm{V}_{1}$ with primary stress. To test this hypothesis, three- and four-syllable words containing $\mathrm{V}_{1} \mathrm{CV}_{2}$ sequences were employed. $\mathrm{V}_{1}$ varied among back low /a/ and front low and mid vowels $/ \mathfrak{x}, \varepsilon /$, while $\mathrm{V}_{2}$ alternated between a reduced vowel /a/ and a high back vowel /u/, as illustrated in (9). 
(9)

\begin{tabular}{|c|c|c|}
\hline VV type & $\hat{v}-\mathrm{v}$ & $\grave{v}-\mathrm{v}$ \\
\hline \multirow[t]{3}{*}{$a-\partial$} & óperàte & òperátion \\
\hline & cómpensàte & còmpensátion \\
\hline & cóncentràte & còncentrátion \\
\hline$a-u$ & dócument & dòcumentátion \\
\hline & pópulàte & pòpulátion \\
\hline æ-ə & ánecdòte & ànecdótal \\
\hline$\varepsilon-\partial$ & démonstràte & dèmonstrátion \\
\hline
\end{tabular}

Tongue body height was compared between when $V_{1}$ was a primary stressed vowel vs. a secondary stressed vowel to see the degree of anticipatory coarticulation from $\mathrm{V}_{2}$. The articulatory results from ultrasound pictures showed that secondary stressed vowels were articulated significantly higher than primary stressed vowels as a result of stronger anticipatory coarticulation from the following unstressed vowel, as illustrated in (10).

a. cóncentràte vs. còncentrátion

b. cómpensàte vs. còmpensátion
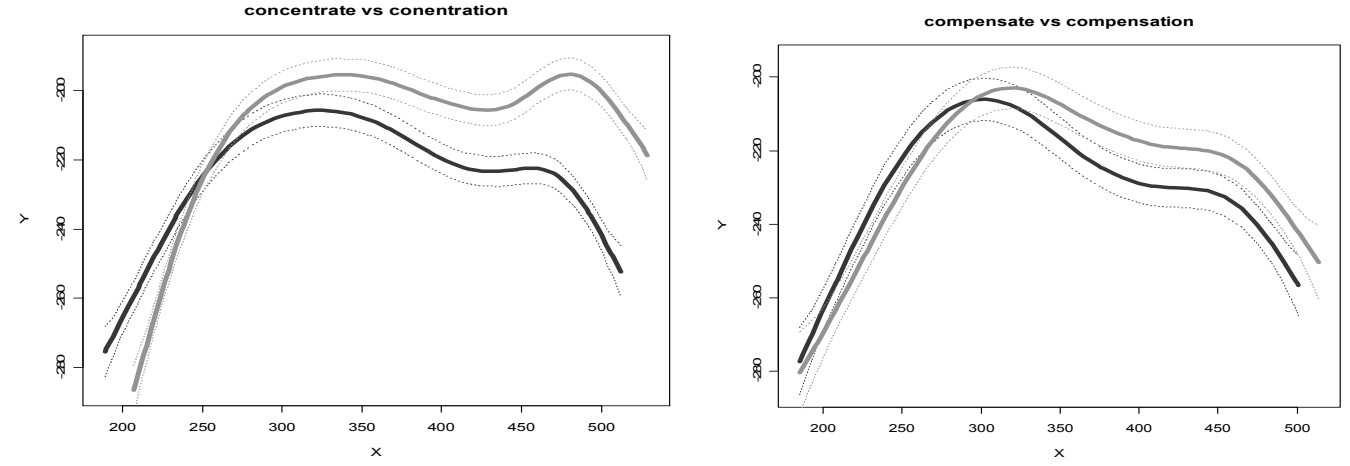

c. démonstràte vs. dèmonstrátion

d. dócument vs. dòcumentátion
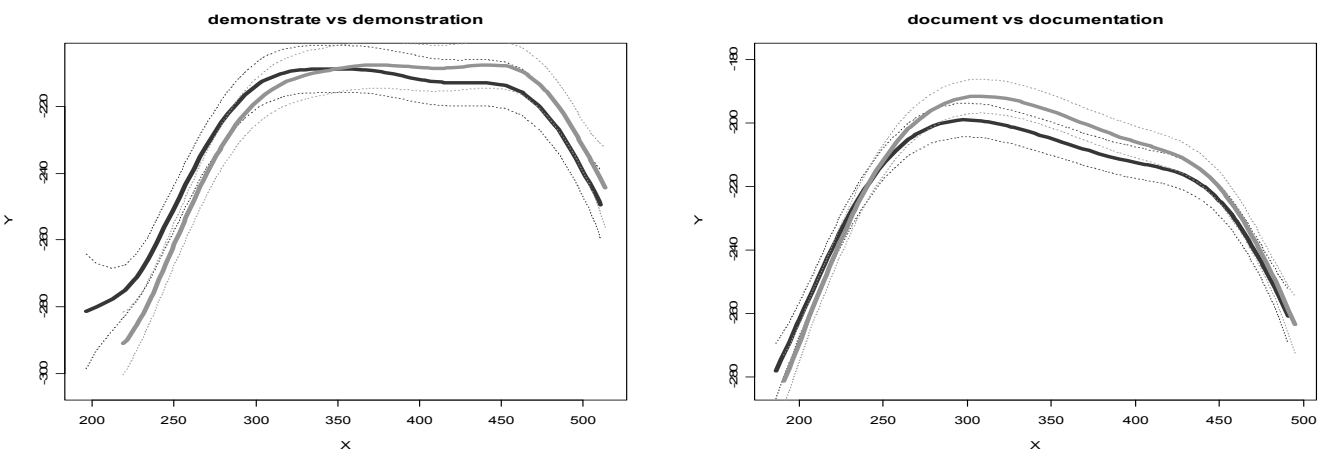

As seen above, the thick lower lines refer to the tongue body position of primary stressed vowels, and the thin upper lines to that of secondary stressed ones. These preliminary articulatory results have several interesting implications. First, they confirm that primary stressed vowels are more resistant to coarticulation than 
Gwanhi Yun

secondary stressed vowels. Second, they indicate nevertheless that even primary and secondary stressed vowels undergo anticipatory coarticulation from following unstressed vowels. Third, they support the "stress-dependent intergestural timing relations" hypothesis, showing that intergestural timing relations are more overlapped between secondary stressed vowels and unstressed vowels than between primary stressed vowels and unstressed ones.

Acoustic experiments were conducted to confirm the articulatory finding of a significant degree of coarticulation only at one time point. The next section describes the experiments and results.

\subsection{Acoustic Experiments: F1/F2 Coarticulation}

In this acoustic experiment, the same four subjects as in the previous acoustic experiments participated in the production of the words in (9). F1/F2 values of low and mid vowels were compared between primary stressed vowels and secondary stressed vowels in order to see how high the vowels are articulated. In total, 160 tokens were analyzed, and F1/F2 values were measured at three time points of $\mathrm{V}_{1}$ in $\mathrm{V}_{1} \mathrm{CV}_{2}$ sequences (i.e. onset, middle, offset) in Praat.

A one-factor within-subjects ANOVA revealed that the effect of stress was significant for F1 differences $(p<0.05)$, but not for F2 differences $(p>0.05)$, as illustrated in (11). These results indicate that secondary stressed vowels were articulated higher than primary stressed vowels because of a stronger influence from the following unstressed vowels. The lack of distinctive influence with respect to backness is due to the fact that most of the vowels for $V_{1}$ and $V_{2}$ are back vowels and thus the likelihood of influence from them is very slight.

Stress effects on F1/F2 between primary and secondary stressed vowels

\begin{tabular}{|l|c|c|c|c|}
\cline { 2 - 5 } \multicolumn{1}{c|}{} & \multicolumn{4}{c|}{ F1 (Hz) } \\
\cline { 2 - 5 } \multicolumn{1}{c|}{} & Mean & Std. Dev. & Difference & $p$-value \\
\hline Primary Stress & 825.3 & 150.6 & 43.7 & $p<0.05$ \\
\hline Secondary Stress & 781.5 & 149.1 & \\
\hline & \multicolumn{4}{c|}{ F2 (Hz) } \\
\hline Primary Stress & 1506.8 & 335.9 & -60.7 & $p>0.05$ \\
\hline Secondary Stress & 1567.6 & 322.1 & & \\
\hline
\end{tabular}

As seen in (11), the pattern of differences in the degree of anticipatory coarticulation at the midpoint of $\mathrm{V}_{1}$ supports the "stress-dependent intergestural timing relations" hypothesis. Next, to confirm these results, the changes in F1 values in $\mathrm{V}_{1}$ were obtained. The results showed that $\mathrm{F} 1$ values at the midpoint and offset points of secondary stressed $\mathrm{V}_{1}$ were significantly lower than those of primary stressed $\mathrm{V}_{1}(p<0.05)$, as illustrated in (12). Interestingly, these findings indicate that the effect of resistance of $V_{1}$ to anticipatory coarticulation from $V_{2}$ already started during the production of $\mathrm{V}_{1}$ in $\mathrm{V}_{1} \mathrm{CV}_{2}$ sequences. 
a. operate vs. operation

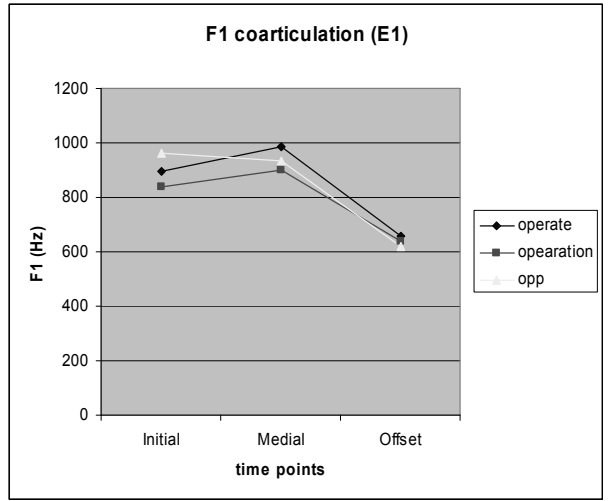

c. document vs. documentation

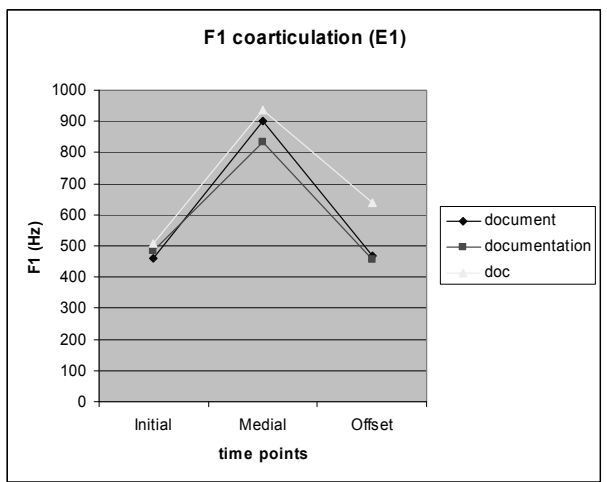

b. compensate vs. compensation

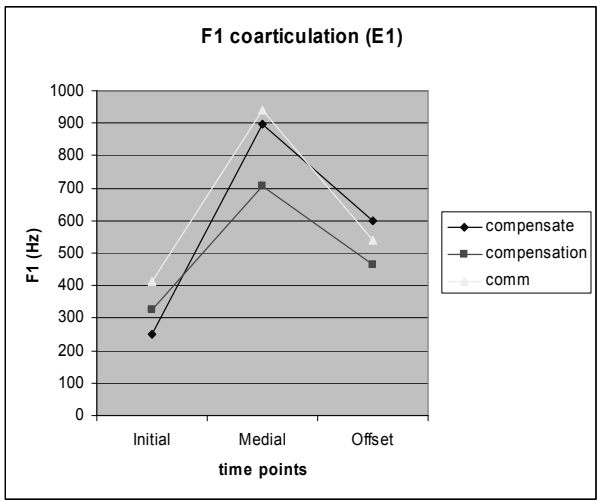

d. anecdote vs. anecdotal

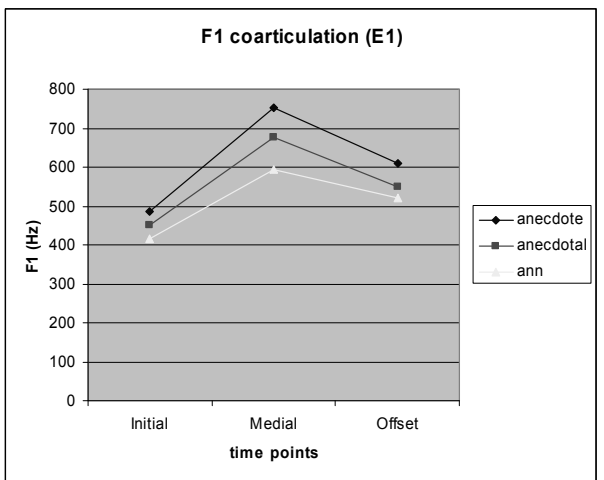

Overall, the acoustic results, especially F1 values, confirm the articulatory results, showing that primary stressed vowels are less influenced by following unstressed vowels than secondary stressed vowels. In summary, both articulatory and acoustic findings indicate that lexical stress affects the degree of vowel coarticulation or resistance to coarticulation. They also show that even unstressed vowels affect primary and secondary stressed vowels in terms of vowel height.

\section{Discussion}

First, both articulatory and acoustic experiments showed that the degree of V-to-V coarticulation is more prominent in high-frequency words than in low-frequency words. Interestingly, the results indicate that frequency affects the subphonemic level (fine phonetic details), as well as segment-internal vowel reduction and suprasegmental rhythmic patterns. There are two possible explanations for frequency effects. First, according to exemplar theory, "reduction is the result of the automation of linguistic production" (Bybee 2002). That is, since highfrequency words involve the repetition of neuromotor patterns, production becomes more efficient, which causes an increase in overlaps of gestures and a decrease in their magnitude. It is reasonable to apply this idea to the greater 
Gwanhi Yun

gestural overlap between vowels in high-frequency lexical items. Second, frequency effects on the degree of coarticulation might be due to formal constraints (Pater 2000, Hammond 2004). If we assume that intergestural timing relations are represented in the input, more prominent coarticulation in high-frequency words can be accounted for by a ranking such as IDENT(GesturalTiming)-LF » OVERLAP(Gestures) » IDENT(GesturalTiming). Or, assuming intergestural timing relations in the output, a ranking such as OVERLAP(GesturalTiming)-HF » IDENT(GesturalTiming) » OVERLAP(Gestures) can be resorted to. Both formal approaches depend on frequency-sensitive faithfulness or markedness constraints which specify intergestural timing relations in the input or output.

Next, both articulatory and acoustic experiments showed that primary stressed vowels are more resistant to (anticipatory) coarticulation than secondary stressed vowels because the former shows more robust articulatory and acoustic properties than the latter (Magen 1984, 1997). Another important contribution of my study is the finding that even unstressed vowels affect primary and secondary stressed vowels, though the degree is different. Thus, concerning the directionality of Vto- $\mathrm{V}$ coarticulation in English, I propose an extended model of bidirectionality of coarticulation, i.e. a revised schema of Magen (1997).

Extended model of bidirectionality of coarticulation
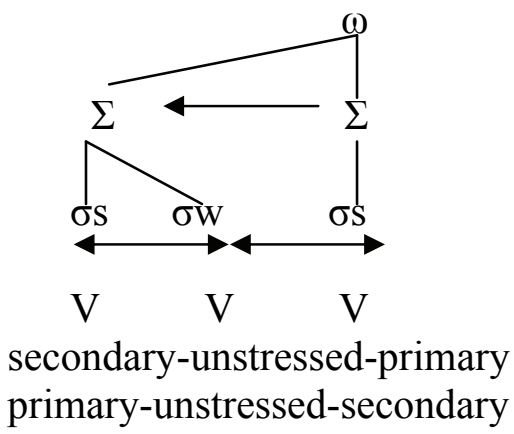

Here we also need to speculate about why stress differences cause such distinctiveness in the degree of coarticulation. One reason may lie in the phonetic realization of stronger stressed vowels. Primary stressed vowels allow less intergestural overlap than secondary stressed vowels because their acoustic properties also involve longer duration, higher amplitude, and/or higher F0 (Edwards et al. 1991). Another reason might be stress-sensitive constraints such as IDENT-FOOT(GesturalTiming), which demands that fixed intergestural timing relations within a foot should be identical in the output, assuming that the different intergestural timing relations are stored in the lexicon.

Based on the experimental results regarding the different intergestural timing relations, I propose the following gestural representations, which reflect lexical frequency and stress effects on V-to-V coarticulation as illustrated in (14). 


\begin{tabular}{|c|c|}
\hline High-frequency words & Low-frequency words \\
\hline Secondary stressed V - Unstressed V & Primary stressed V - Unstressed V \\
\hline V -- V & $\begin{array}{ll} & V\end{array}$ \\
\hline$\overleftrightarrow{\text { more overlap }}$ & less overlap \\
\hline
\end{tabular}

The experimental results in this study make some contributions. First, they provide more evidence that abstract intergestural timing relations can be incorporated into formal grammar. Second, they open a way to enrich output representations, reflecting approximate articulatory properties much closer to actual output pronunciation.

\section{Conclusions}

This study showed that the degree of V-to- $\mathrm{V}$ coarticulation is highly conditioned both by lexical frequency and stress to some extent. Furthermore, it suggests that phonetic or lexical representation can incorporate the degree of intergestural timing relations either in the output or in the input, in case we assume an exemplar model or a formal constraint-based model (Cho 1998, Gafos 2002).

\section{References}

Browman, Catherine, and Louis Goldstein. 1989. Articulatory Gestures as Phonological Units. Phonology 6:201-252.

Bush, Nathan. 2001. Frequency Effects and Word-Boundary Palatalization in English. In J. Bybee and P. Hopper, eds., Frequency and the Emergence of Linguistic Structure. John Benjamins.

Bybee, Joan. 2002. Word Frequency and Context of Use in the Lexical Diffusion of Phonetically Conditioned Sound Change. Language Variation and Change 14:261-290.

Byrd, Dani. 1996. Influences on Articulatory Timing in Consonant Sequences. Journal of Phonetics 24:209-244.

Cho, Taehong. 1998. Intergestural Timing and Overlap in Korean Palatalization: An Optimality-Theoretic Approach. In D. Silva, ed., Japanese/Korean Linguistics 8:261-276. Stanford: CSLI Publications.

Davidson, Lisa. 2005. Comparing Tongue Shapes from Ultrasound Imaging Smoothing Spline Analysis of Variance. Ms., New York University. 
Gwanhi Yun

Edwards, Jan, Mary Beckman, and Janet Fletcher. 1991. The Articulatory Kinematics of Final Lengthening. Journal of the Acoustical Society of America 89:369-382.

Fidelholtz, James. 1975. Word Frequency and Vowel Reduction in English. In Proceedings of the Annual Meeting of the Chicago Linguistic Society 11:200-213.

Fowler, Carol. 1981. Production and Perception of Coarticulation among Stressed and Unstressed Vowels. Journal of Speech and Hearing Research 46:127-139.

Gafos, Adamantios. 2002. A Grammar of Gestural Coordination. Natural Language and Linguistic Theory 20:269-337.

Hammond, Michael. 1988. Constraining Metrical Theory: A Modular Theory of Rhythm and Destressing. New York: Garland.

Hammond, Michael. 2004. Frequency, Cyclicity, and Optimality. In Proceedings of the $2^{\text {nd }}$ Seoul International Phonology Conference. Seoul National University.

Hayes, Bruce. 1984. The Phonology of Rhythm in English. Linguistic Inquiry 15:33-47.

Hooper, Joan. 1976. Word Frequency in Lexical Diffusion and the Source of Morphophonological Change. In W. Christie, ed., Current Progress in Historical Linguistics, 96-105. Amsterdam: North Holland.

Liberman, Mark, and Alan Prince. 1977. On Stress and Linguistic Rhythm. Linguistic Inquiry 8:249-336.

Magen, Harriet. 1984. Vowel-to-Vowel Coarticulation in English and Japanese. Journal of the Acoustical Society of America Supplement 75:S41.

Magen, Harriet. 1997. The Extent of Vowel-to-Vowel Coarticulation in English. Journal of Phonetics 25:187-205.

Manuel, Sharon. 1987. Acoustic and Perceptual Consequences of Vowel-toVowel Coarticulation in Three Bantu Languages. Ph.D. diss., Yale University.

Öhman, Sven. 1966. Coarticulation in VCV Sequences: Spectrographic Measurements. Journal of the Acoustical Society of America 39:151-168.

Pater, Joe. 2000. Non-Uniformity in English Secondary Stress: The Role of Ranked and Lexically Specific Constraints. Phonology 17:237-274.

Whalen, Douglas H. 1990. Coarticulation is Largely Planned. Journal of Phonetics 18:3-35.

Gwanhi Yun

Department of Linguistics

PO Box 210028

The University of Arizona

Tucson, AZ 85721-0028

ghy@email.arizona.edu 